\title{
Research on the effect of yield strength of circular saw blade on roll tensioning process
}

\author{
Bo Li ${ }^{1} \cdot$ Zhankuan Zhang ${ }^{1}$
}

Received: 17 October 2016/Accepted: 1 December 2016/Published online: 20 December 2016

(C) The Japan Wood Research Society 2016

\begin{abstract}
In this paper, a 2-D and 3-D finite element model of roll tensioning process of circular saw blade were established by Static/General module of ABAQUS software based on finite element method. The rolling force and tensioning stress distribution of circular saw blade were calculated by these two models which were proved to be true and reliable. The effects of yield strength of circular saw blade on tensioning stress distribution and rolling force were studied. The research achievements showed that a circular saw blade made with high yield strength obtained a higher tangential compressive stress and radial compressive stress in the rolled region during roll tensioning process, which has both advantages and disadvantages for the stability of the saw blade. Besides, a circular saw blade made with high yield strength also put forward higher requirements for roll tensioning equipment because of the large rolling force during roll tensioning process.
\end{abstract}

Keywords Circular saw blade - Roll tensioning - Finite element method

\section{Introduction}

Circular saw blade is an important tool and is widely used in wood industry. Its stability, cutting precision, and material-saving ability are the most important features, especially for wood processing industry because of the shortage of precious wood. The Chinese government

\section{Bo Li}

libohongxing@sina.com

1 Research Institute of Wood Industry, Chinese Academy of Forestry, Beijing 100091, China strongly supports the improvement of timber utilization. Therefore, circular saw blade is becoming thinner and thinner currently for reducing kerf loss and improving the utilization of materials.

However, thermal stress is produced when circular saw blade is working, because the temperature at the edge of the blade is higher than that in other regions of the blade. It will cause high tangential compressive stress on the edge of the circular saw blade, causing a buckling deformation that reduces cutting precision, increases kerf loss, and shortens the saw's life [1,2]. Thin circular saw blade is more easily affected by thermal stress. For saving materials, the stability of saw blade is very important, especially for thin circular saw blade.

Tensioning is the most important and advanced technological process for production of circular saw blade for avoiding the above-mentioned phenomenon. Among all the tensioning processes, roll tensioning process is most widely applied in the cutting tool industry. The tangential tensile tensioning stress field is produced which can compensate for the tangential compressive stress caused by thermal stress and improve the stability of circular saw blade [3-5]. However, circular saw blade can also obtain radial compressive tensioning stress during roll tensioning process which is easy for the blade to lose stability and buckle into a "dish" shape. The thin circular saw blade requires higher tangential tensile tensioning stress and lower radial compressive tensioning stress for maintaining stability, which brings a challenge to roll tensioning process of thin circular saw blade.

At present, the effects of tensioning on the dynamic stability of the blades have been mainly focused [6-16]. The generation of tensioning stress during tensioning processes has been studied by a few researchers. A theoretical model for roll tensioning process was established by 
Szymani and Mote [2]. A model for roll tensioning process was established by Nicoletti based on the finite element method [17]. A finite element model (FEM) for roll tensioning process, which allowed for the investigation of various roll tensioning parameters, was developed by Heisel [18]. A mathematical model of tangential tensioning stress in the edge of a circular saw blade tensioned by multi-spot pressure was established for the quality control of circular saw blades by $\mathrm{Li}$ [19].

Yield strength is the lowest stress value when plastic deformation is produced, which is an important indicator for metal materials and has a great effect on metal forming process such as roll tensioning process. Circular saw blade with different yield strength could obtain tangential tensile and radial compressive tensioning stress with different values, and different rolling force will be applied to the roll for making the blade to produce plastic deformation.

However, to date, for circular saw blades, there is no related research about the effect of yield strength on the generation of tensioning stress during roll tensioning process. Therefore, the effect of yield strength of circular saw blade on the generation of tensioning stress during roll tensioning process was analyzed in this paper, which can demonstrate the effect of yield strength on roll tensioning process.

\section{Materials and methods}

\section{2-D FEM model for calculation of tensioning stress}

FEM is used for residual stress analysis in many elasticplastic forming process and is proved to be the most suitable method [20, 21]. Therefore, FEM was chosen for modeling analysis of roll tensioning process.

Roll tensioning process was assumed to be an axially symmetrical problem in planar stress [2]. A half model was established considering the symmetry of the model by Static/General module of ABAQUS, as shown in Fig. 1. The 2-D FEM model was used to calculate tensioning stress because it can truly reflect the elastic-plastic deformation of circular saw blade after roll tensioning process, taking into account its accuracy and efficiency at the same time.

In step 1, the roll moved slowly down and elastic-plastic deformation was produced to the saw blade. In step 2, the roll slowly raised and the saw blade was no longer under any load. The residual stress of saw blade was the tensioning stress.

A vertical displacement constraint was applied to the axial center plane. The 4 node axially symmetrical reduced integral element CAX4R was chosen for the circular saw blade. The number of elements was increased within the contact area between the circular saw blade and the roll for improving the accuracy of calculation, as shown in Fig. 1. The roll was modeled as an analytical rigid body because the deformation of roll is not the focus of this paper, which can also improve the calculation efficiency. Vertical downward displacement was applied to the roll. Coulomb friction model was applied between the circular saw blade and the roll. The friction coefficient was set to 0.1 .

The material model of circular saw blade was set as linear strengthening elastic-plastic model (bilinear model) because the plastic deformation of circular saw blade during roll tensioning process was very little. Its Elastic modulus and Poisson ratio were $210 \mathrm{GPa}$ and 0.3 .
Fig. 1 2-D FEM model of roll tensioning process (a) Axial symmetry model

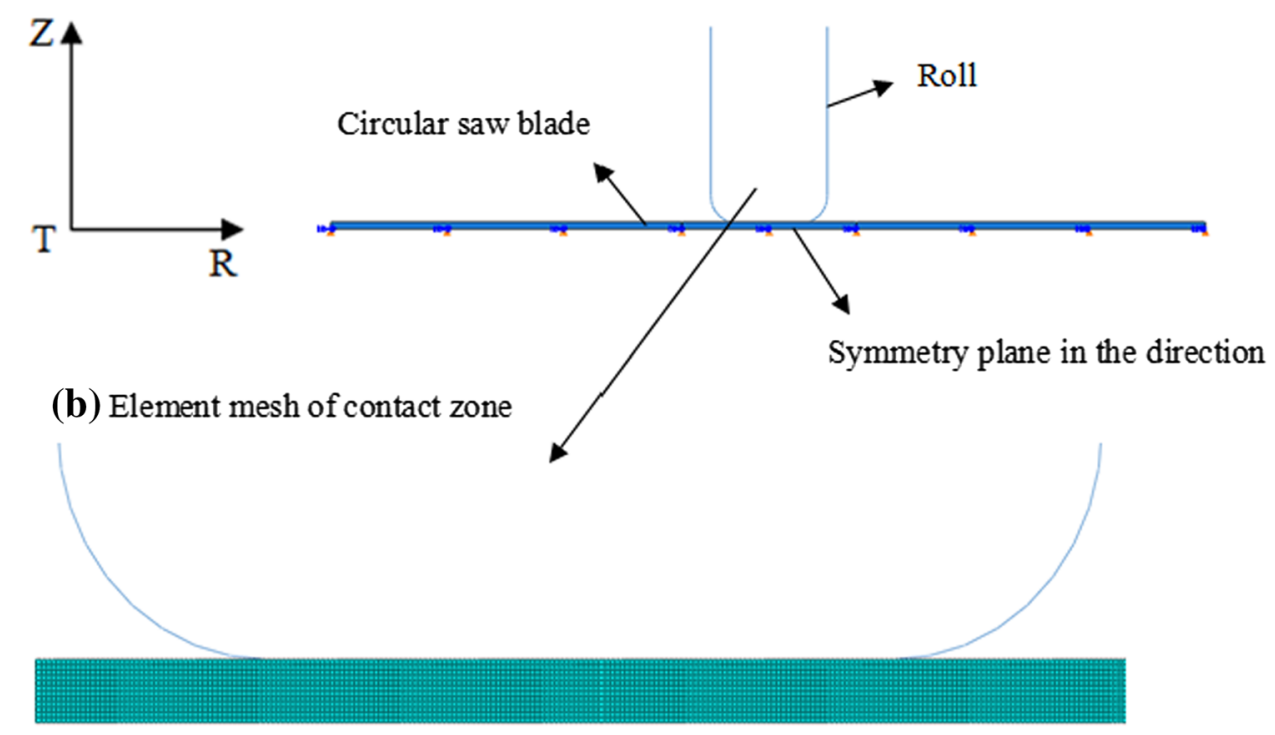


The dimension of circular saw blade was shown below. The diameter was $360 \mathrm{~mm}$; the thickness was $2.2 \mathrm{~mm}$; and the diameter of the hole was $60 \mathrm{~mm}$. The dent depth of rolled region was $10 \mu \mathrm{m}$. The radius of rolled region was $105 \mathrm{~mm}$.

\section{3-D FEM model for calculation of rolling force}

A half model was established considering the symmetry of the model by Static/General Module of ABAQUS, as shown in Fig. 2. The 3-D FEM model was used to calculate rolling force, because it can truly reflect the contact status between the roll and the saw blade. Taking into account its efficiency, the roll in the 3-D FEM model only needs to rotate a small angle, with the rolling force reaching a steady state. The dimension of roll was shown in Fig. 3. Its radius was $30 \mathrm{~mm}$.

In step 1, the roll moved slowly down and elastic-plastic deformation was produced to the saw blade. In step 2, the roll began to rotate and the rotation of the roll drove the saw blade to rotate. The vertical force acting on the roll calculated by the model was the rolling force.

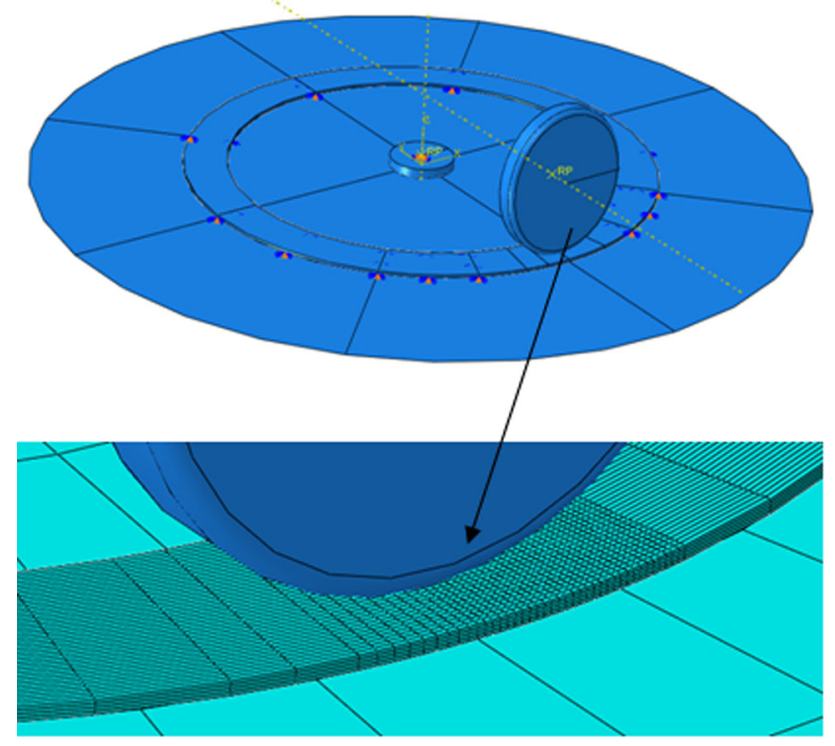

Fig. 2 3-D FEM model of roll tensioning process

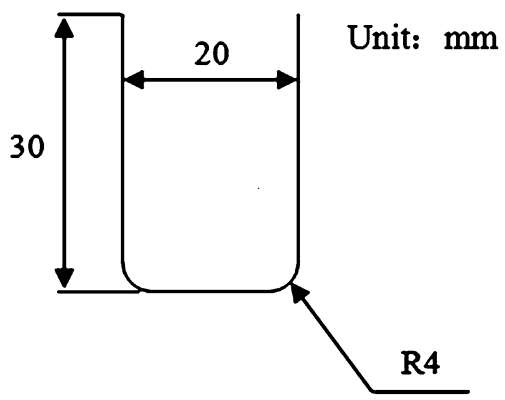

Fig. 3 Schematic diagram of roll
The three-dimensional 8 node reduced integral element C3D8R was chosen for the rolling ring of circular saw blade and the 4-node general-purpose reduced integral shell S4R was chosen for the medial and lateral regions, which can reduce the number of elements to the maximum extent and improve the computational efficiency. The three parts were tied together through the way of shell-to-solid coupling. The number of elements was increased within the contact area between the circular saw blade and the roll for improving the accuracy of calculation, as shown in Fig. 3. The other parameters of the 3-D FEM model were the same as the 2-D model.

\section{Results}

\section{Validation of the FEM model}

Roll tensioning experiment was done. Parameters of circular saw blade were shown below: material, $65 \mathrm{Mn}$; hardness, HRC42; yield strength, $430 \mathrm{MPa}$; strain hardening rate, $1000 \mathrm{MPa}$. Parameters of the roll were shown below: hardness, HRC60. The other parameters of the saw blade and the roll were the same as the FEM model. The dent depth of rolled region was $10 \mu \mathrm{m}$ and tensioning stress distribution along the radial direction of upper surface in circular saw blade was measured by X-ray stress meter.

The vertical downward displacement applied to the roll in the 2-D FEM model was adjusted for making the depth of rolled region to be $10 \mu \mathrm{m}$, and the tensioning stress of nodes along the radial direction of upper surface in circular saw blade was obtained. The contrast between the tensioning stress of the circular saw blade calculated by the FEM model and the measured results in the radial path was shown in Fig. 4.

As shown in Fig. 4, the tensioning stress distribution of the circular saw blade calculated by the FEM model followed the same trend as previous research results $[2,6,18]$. The values of tensioning stress of the circular saw blade calculated by the FEM model and the measured results in radial path of the circular saw blade were similar in most regions. The results mentioned above demonstrated that the tensioning stress of the circular saw blade calculated by the model in this paper was true and reliable. The tensioning stress distribution of circular saw blade after roll tensioning process was the key analysis object in the following.

As shown in Fig. 5, the rolling force increased slowly during pressing process of roll. The rolling force reached a steady state during rolling process. As shown in Fig. 6a, the rolling force was increased with the vertical downward displacement of the roll. Elastic-plastic deformation was produced in the contact region of circular saw blade. To obtain the dent depth $10 \mu \mathrm{m}$ of rolled region, the vertical 


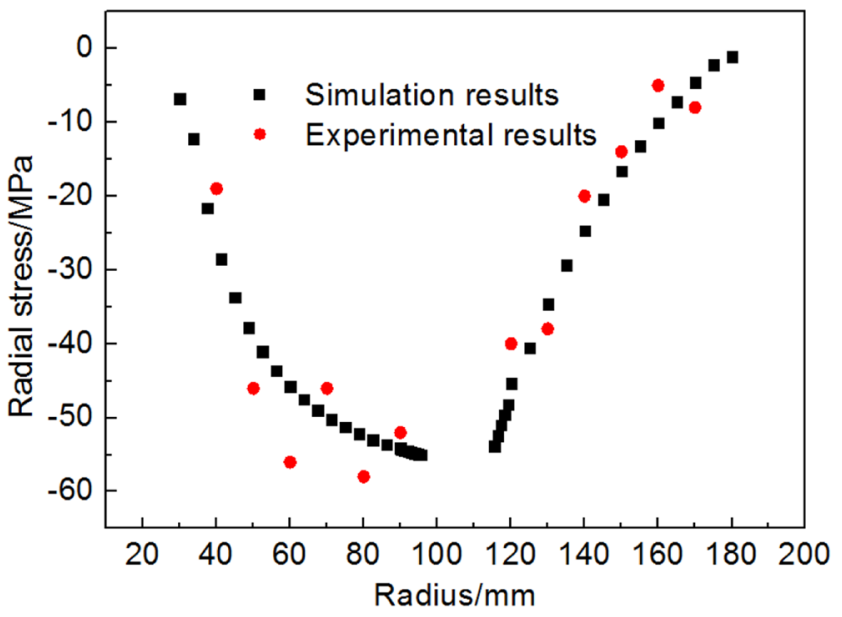

(a) Radial stress distribution

Fig. 4 Contrast between the simulation and the measured results

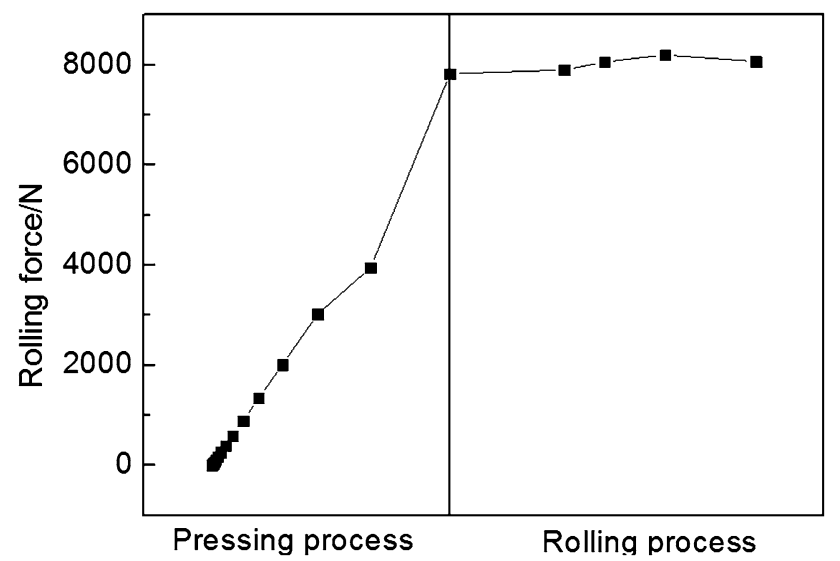

Fig. 5 The change of rolling force during roll tensioning process

downward displacement applied to the roll was $13.4 \mu \mathrm{m}$ because of the rebound deformation of circular saw blade. As shown in Fig. 6b, the rolling force was about $8000 \mathrm{~N}$ and was not changed approximately with the rotation angle of the roll during rolling process. The elastic-plastic deformation was produced in ring rolling region during this process. The calculation result of rolling force was in conformity with the actual situation. Rolling force of steady state was the object of analysis in the following too.

\section{The effect of yield strength of circular saw blade on tensioning stress distribution and rolling force}

The yield strengths of the circular saw blade were: 300 , 600, 900, and $1200 \mathrm{MPa}$. Their strain hardening rate was $1000 \mathrm{MPa}$. To obtain the same dent depth $10 \mu \mathrm{m}$ of rolled region, the vertical downward displacement applied to the roll was adjusted because the rebound deformation of circular saw blade with different yield strength was different

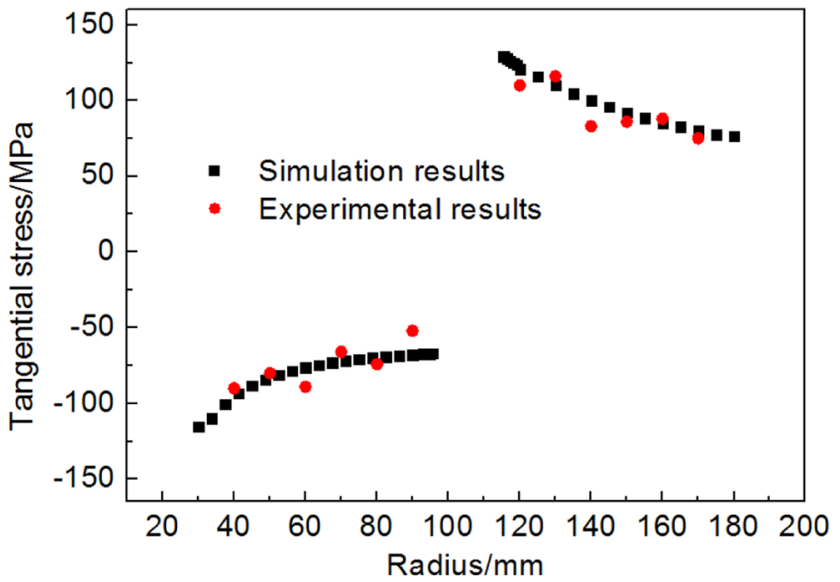

(b) Tangential stress distribution

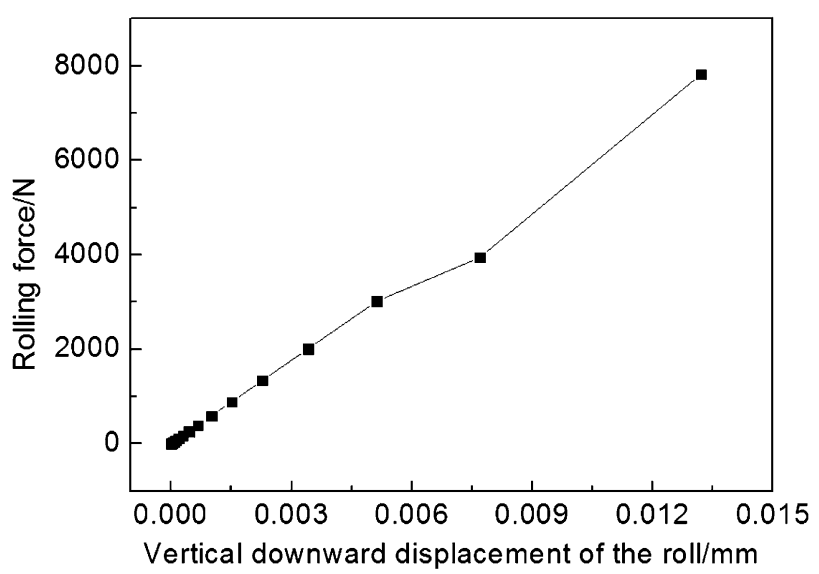

(a) Pressing process

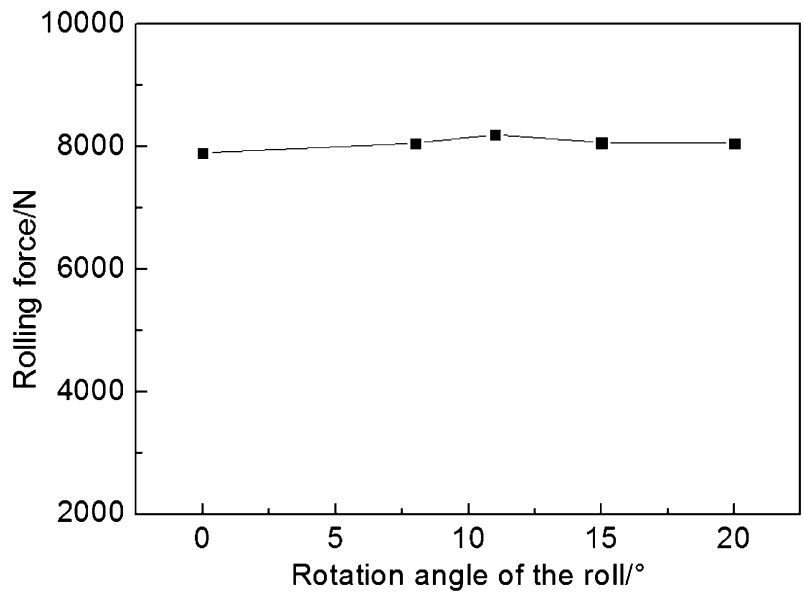

(b) Rolling process

Fig. 6 The change of rolling force during pressing and rolling process 
and the rebound deformation was increased with yield strength. Vertical downward displacement applied to the roll was shown in Table 1.

As shown in Fig. 7, the radial tensioning stress and tangential tensioning stress in outer and inner side of rolled

Table 1 Vertical downward displacement applied to the roll

\begin{tabular}{ll}
\hline Yield strength/MPa & Vertical downward displacement/ $\mu \mathrm{m}$ \\
\hline 300 & 12.0 \\
600 & 14.0 \\
900 & 15.6 \\
1200 & 17.2 \\
\hline
\end{tabular}

region were approximately the same, they were not affected by the yield strength of circular saw blade because the outer and inner side of rolled region were elastic deformation zone. But in rolled region, the radial tensioning compressive stress and tangential tensioning compressive stress were all increased with yield strength of circular saw blade because plastic deformation resistance was increased with yield strength. When yield strength of circular saw blade was $1200 \mathrm{MPa}$, the maximum radial tensioning compressive stress and tangential tensioning compressive stress had reached to 180 and $300 \mathrm{MPa}$.

For tangential tensioning stress, the tangential tensioning stress difference between outer edge of the saw blade and rolled region was increased with yield strength when

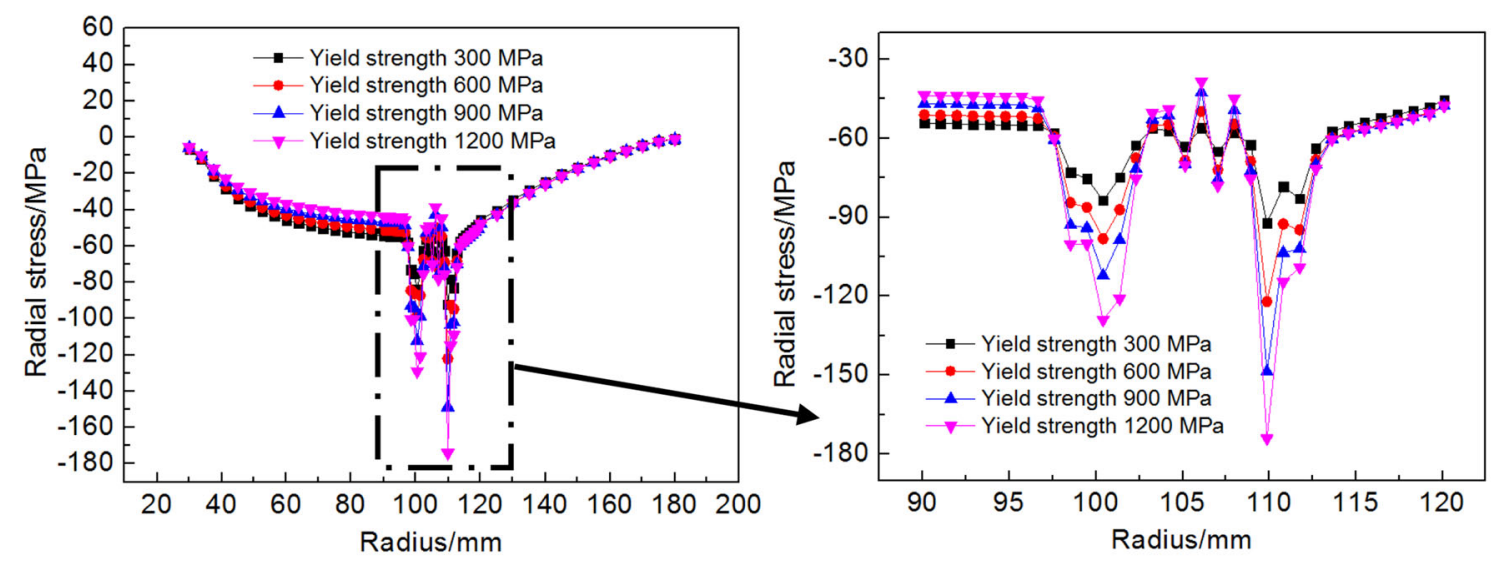

(a) Radial stress distribution

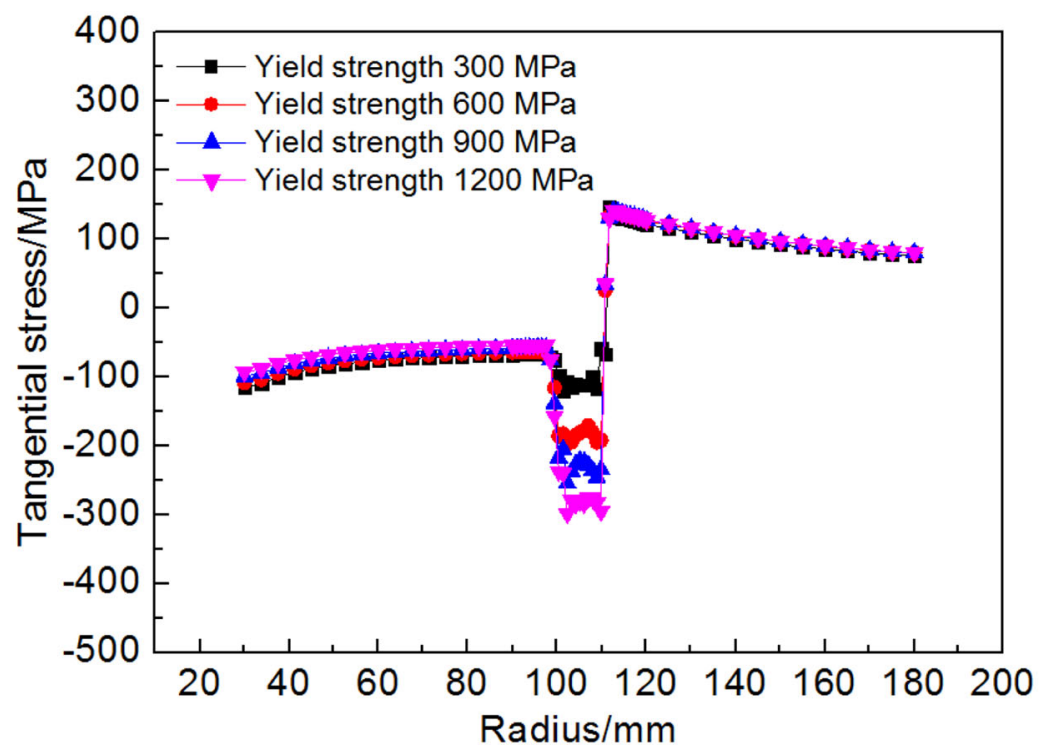

(b) Tangential stress distribution

Fig. 7 Tensioning stress of circular saw blade with different yield strength 


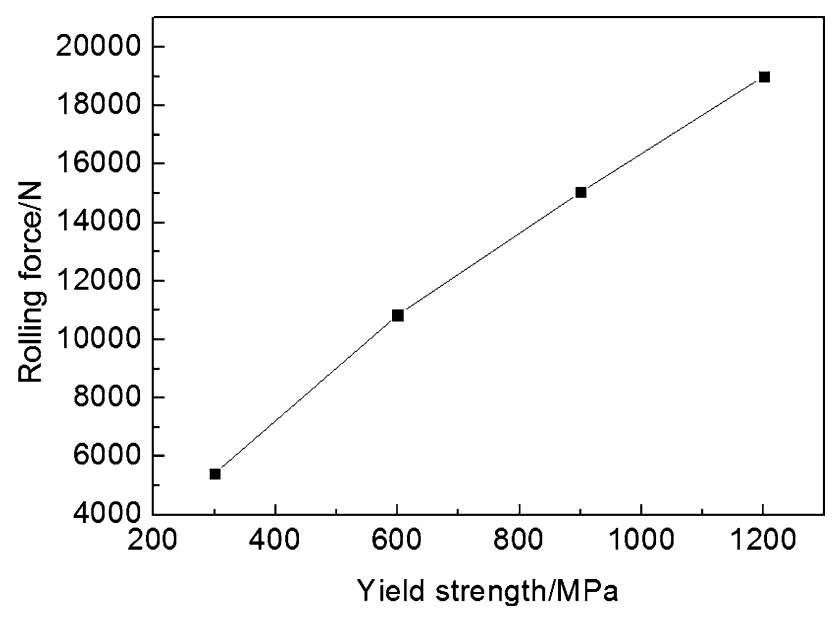

Fig. 8 The change of rolling force with yield strength when dent depth of rolled region is $10 \mu \mathrm{m}$

circular saw blade was under the same deformation, which meant that the tensioning effect was improved with the increase of yield strength, because the greater tangential tensioning stress difference between edge of the saw blade and rolled region meant that the circular saw blade could maintain stability during large temperature differences when it was at work.

However, for radial tensioning stress, the radial tensioning stress difference between inner edge of the saw blade and rolled region was increased with yield strength when circular saw blade was under the same deformation, which was not conducive to the improvement of the stability of the saw blade because the stress state is easy for the blade to lose stability and buckle into a "dish" shape.

As shown in Fig. 8, rolling force was increased linearly with yield strength of circular saw blade when dent depth of rolled region is $10 \mu \mathrm{m}$ because plastic deformation resistance was increased with yield strength. When yield strength of circular saw blade was $1200 \mathrm{MPa}$, the rolling force had reached to $19.2 \mathrm{kN}$. The substantial increase in rolling force brought challenges to the roll tensioning equipment of circular saw blade.

\section{Discussion}

In this study, a 2-D and 3-D FEM model of roll tensioning process was established by theoretical analysis and calculation. The effects of yield strength of circular saw blade on the tensioning stress distribution and rolling force were studied by these two models.

The simulation results showed that the circular saw blade with higher yield strength could achieve a higher tangential compressive stress and radial compressive stress in the rolled region during roll tensioning process, which has both advantages and disadvantages for the stability of the saw blade. For circular saw blades with different yield strength, the dent depth and position of rolled region needs to be adjusted for obtaining optimal tensioning effect, which will be an important research direction for roll tensioning process.

The simulation results showed that rolling force was increased linearly with yield strength of circular saw blade, which brought challenges to the roll tensioning equipment of circular saw blade.

Acknowledgements We gratefully acknowledge the financial support of National Natural Science Foundation of China (No. 31600458) and (No. 31270605).

\section{References}

1. Li B, Zhang ZK, Li WG, Peng XR (2015) A numerical simulation on multi-spot pressure tensioning process of circular saw blade. J Wood Sci 61:578-585

2. Szymani R, Mote CD Jr (1979) Theoretical and experimental analysis of circular saw tensioning. Wood Sci Technol 13(3):211-237

3. Umetsu J, Noguchi M, Wada K, Fujii Y (1989) Confirmation of $\varphi$ splitting in the distribution of residual stress in tensioning circular saws. Mokuzai Gakkaishi 35:856-858

4. Umetsu J, Noguchi M, Matsumoto I (1994) Measuring residual stresses in tensioned circular saws using X-rays (in Japanese). Mokuzai Gakkaishi 40:268-273

5. Li B, Zhang ZK, Li WG, Peng XR (2015) Effect of yield strength of a circular saw blade on the multi-spot pressure tensioning process. BioResources 10(4):7501-7510

6. Szymani R, Mote CD Jr (1974) A review of residual stresses and tensioning in circular saws. Wood Sci Technol 8(2):148-161

7. Schajer GS, Mote CD Jr (1983) Analysis of roll tensioning and its influence on circular saw stability. Wood Sci Technol 17(4):287-302

8. Schajer GS, Mote CD Jr (1984) Analysis of optimal roll tensioning for circular saw stability. Wood Fiber Sci 16(3):323-338

9. Ishihara M, Noda N, Ootao Y (2010) Analysis of dynamic characteristics of rotating circular saw subjected to thermal loading and tensioning. J Therm Stresses 33(5):501-517

10. Ishihara M, Murakami H, Ootao Y (2012) Genetic algorithm optimization for tensioning in a rotating circular saw under a thermal load. J Therm Stresses 35(12):1057-1075

11. Stakhiev YM (2004) Coordination of saw blade tensioning with rotation speed: myth or reality. Holz Roh Werkst 62(4):313-315

12. Carlin JF, Appl FC, Bridwell HC (1975) Effects of tensioning on buckling and vibration of circular saw blades. J Eng for Ind 97(1):37-48

13. Schajer GS, Kishimoto KJ (1996) High-speed circular sawing using temporary tensioning. Holz Roh Werkst 54(6):361-367

14. Cristóvão L, Ekeva M, Grönlund A (2012) Natural frequencies of roll-tensioned circular saw blades: effects of roller loads, number of grooves, and groove positions. BioResources 7(2):2209-2219

15. Gospodaric B, Bucar B, Fajdiga G (2015) Active vibration control of circular saw blades. Eur J Wood Wood Prod 73(2):151-158 
16. Zhang MS, Zhang Y, Ke JJ, Li XW, Cheng LB (2014) The influence of tangential roller pressure on the stability of circular saw blade. Appl Mech Mater 614:32-35

17. Nicoletti N, Fendeleur D, Nilly L, Renner M (1996) Using finite elements to model circular saw roll tensioning. Holz Roh Werkst 54(2):99-104

18. Heisel U, Stehle T, Ghassemi H (2014) H (2014) A simulation model for analysis of roll tensioning of circular saw blade. Adv Mater Res 1018(2014):57-66
19. Li B, Zhang ZK, Li WG, Peng XR (2015) Model for tangential tensioning stress in the edge of circular saw blades tensioned by multi-spot pressure. BioResources 10(2):3798-3810

20. Jiang ZL, Liu YM, Li L, Shao WX (2014) A novel prediction model for thin plate deflections considering milling residual stresses. Int J Adv Manuf Technol 74(1-4):37-45

21. Moazeni B, Salimi M (2015) Investigations on relations between shape defects and thickness profile variations in thin flat rolling. Int J Adv Manuf Technol 77(5-8):1315-1331 